\title{
La resistencia de la agricultura familiar tradicional en el Chaco, Argentina
}

\section{The resistance of traditional family agriculture in El Chaco, Argentina}

\author{
Cristina O felia Valenzuela \\ Ángel VITO-SCAVO*
}

\begin{abstract}
This articl e analyses the resistance of traditional family agricultural schemes to the implicit transformations of technological evolution and new organisation models of agricultural production. This resistance is analysed in its individual and collective manifestations, as well as from the point of view of its purposes of rescue and permanence of a productivity identity, built upon practices and specific agents in a peripheral province of Argentina.
\end{abstract}

Keywords: productivity models, territoriality, identity, multiscale dialectics, Argentina.

\begin{abstract}
Resumen
En este artículo se analiza la resistencia de los esquemas agrícolas tradicionales de tipo familiar a las transformaciones implícitas en la evolución tecnológica y los nuevos modelos de organización de la producción agrícola. Esta resistencia se analiza en sus manifestaciones individuales y colectivas y en su propósito de rescate y permanencia de una identidad productiva, construida en torno a prácticas y agentes específicos en una provincia periférica argentina.
\end{abstract}

Palabras clave: modelos productivos, territorialidad, identidad, dialéctica multiescalar, Argentina.

* Instituto de Investigaciones Geohistóricas-Consejo Nacional de Investigaciones Científicas y Técnicas (Conicet), Argentina. Correos-e: cvalenzu@ bib.unne.edu.ar, angelscav01981@yahoo.com.ar. 


\section{Introducción}

El objetivo de este trabajo es exponer la dinámica en que coexisten lógicas de actuación en la actividad agrícola de un territorio concreto: el Chaco, provincia periférica del norte argentino. Esta jurisdicción exhibió, en los últimos 10 años, la permanencia simultánea de dos modalidades productivas específicas sustentadas en agentes diferenciados: por una parte, los esquemas tradicionales de tipo familiar arraigados históricamente en su identidad productiva y territorial en el cultivo algodonero, como práctica heredada por generaciones; y por otra, los nuevos modelos y estrategias diferenciadas de apropiación y uso del suelo asociados a la soya transgénica y su tecnología de insumos y procesos.

El periodo estudiado (1996-2007) abarca la etapa transcurrida entre la difusión masiva de la soya RR en el país, en el marco del Plan M acroeconómico de Convertibilidad (que implicó desregulación, apertura económica y paridad cambiaria), y los cambios que suscitó el final de este plan a partir de la devaluación en 2002, así como el salto exportador argentino en el mercado de oleaginosas.

Este artículo aporta una mirada multiescalar que examina la dinámica nacional, provincial y local, ámbito en el que el estudio empírico de casos se desarrolla en el área algodonera tradicional del Chaco (Pampa Napenay y Colonia J osé $\mathrm{M}$ ármol, cercanas a Roque Sáenz Peña, capital nacional del algodón). Los resultados se apoyan sobre todo en fuentes primarias (entrevistas en profundidad, parcialmente estructuradas, a productores que consideramos informantes clave y representantes de organizaciones sociales), periodísticas, estadísticas, bibliográficas y documentales relativas al tema.

El texto se estructura en tres partes: la primera sección especifica la orientación metodológica; en la segunda se contextualizan las transformaciones del sector agrario argentino en los últimos 15 años; y en la tercera se analiza la compleja dinámica entre las nuevas tendencias productivas y las modalidades de resistencia que sostienen los pequeños y medianos productores que persiguen la permanencia de la familia en el campo y la preservación de sus tierras. Esta resistencia se examina en sus manifestaciones individuales y colectivas, en este último caso a partir de una organización de mujeres productoras e integrantes de familias algodoneras. 
El trasfondo más amplio en el que se inserta este estudio de casos remite a la discusión acerca del rescate de alternativas productivas que reflejan identidades históricas construidas y arraigadas espacialmente, que pueden actuar como recursos para el desarrollo y cuya recuperación permitiría a sus agentes conservar el sentimiento local de pertenencia, sin negar al territorio una apertura hacia el mundo, que posibilite una coexistencia no antagónica con otras lógicas productivas.

\section{Relevancia del problema y contextualización del área de estudio}

\subsection{La historia multiescalar de la trama territorial}

En los últimos 15 años, la creciente internacionalización de la economía y de las redes de información puso de manifiesto lo que David Harvey, en su estudio sobre el desarrollo geográfico desigual, concibe como la vulnerabilidad sel ectiva que expone de manera desigual a las poblaciones a efectos como el desempleo, la degradación de los niveles de vida, así como a la pérdida de recursos, opciones y calidades ambientales en diversas escalas espaciales, y que al mismo tiempo "concentra la riqueza y el poder y más oportunidades políticas y económicas en unas cuantas localizaciones selectivas y dentro de unos cuantos estratos restringidos de población" (2003: 102). Esa fragilidad diferenciada se manifiesta ante la dinámica de un mismo vector en distintas áreas de incidencia. En este sentido, el área de estudio escogida constituye un ejemplo de este tipo de procesos en la medida en que exhibe un perfil -que se explica en las siguientes páginas- de mayor debilidad e inestabilidad, así como una menor capacidad de reacción (ya sea de adaptación o de resistencia) ante vectores similares, como los derivados de las nuevas modalidades productivas y de comercialización de la agricultura difundidas en Argentina en los últimos años.

El tema del disímil efecto que las nuevas tendencias productivas del sector agrícola tiene en territorios con distintas capacidades de reacción a los impulsos del crecimiento y la modernización, se ha abordado desde diversas perspectivas y enfoques de los cuales interesa destacar, por ejemplo, los enfoques económicos del desequilibrio, de orientación keynesiana (M yrdal, 1957; H irschman, 1958; Boudeville, 1966; Perroux, 1991), que analizaron los mecanismos de transmisión funcional y territorial de los impulsos 
del crecimiento y sus efectos polarizantes para el desarrollo económico (G utman y Gorenstein, 2003: 566); o partiendo de la preocupación por las relaciones desiguales de los procesos de acumulación del capital, la aportación de los estudios sobre el desarrollo regional y los mecanismos de generación y apropiación de excedentes, de acuerdo con el poder económico diferencial de los distintos agentes que analizaron la dimensión espacial de las dinámicas de acumulación y reproducción social (H arvey, 2003, 2007; Coraggio, 1971, 2000; Rofman, 1986, 1995, 1999, 2000, 2002, 2003; R ofman y García, 2007, entre otros).

Las diferencias geográficas resultantes de legados históricos y geográficos, se sostienen y reproducen o reconfiguran por los procesos político-económicos y socioecológicos que tienen lugar en el presente, los cuales adquieren particular relevancia a partir de la consolidación de los procesos de globalización económica, política y cultural y la aceleración del desarrollo científico y tecnológico. Los territorios exhiben distintos niveles de debilidad, fragilidad e inestabilidad, así como diversas posibilidades e intensidades de reacción. Así, cobra relevancia el papel que en las relaciones de producción reviste la ubicación relativa a un contexto, la especificidad y la inercia histórica inherentes a una situación espacial particular, como factor de desarrollo diferenciado. A ello se agrega el desigual reparto cuantitativo y cualitativo de recursos, naturales y humanos, que genera contrastes en el volumen y tipo de actividades existentes en cada área.

Desde esa perspectiva, los motivos para seleccionar una provincia periférica subyacen en su originalidad dentro de la dinámica agrícola nacional como la principal jurisdicción productora de algodón que, desde 1930 hasta la actualidad, aportó históricamente entre $70 \%$ y $85 \%$ del total cosechado. La especialización territorial en productos singulares o complementarios de la producción de las provincias centrales o pampeanas no fue un proceso neutro, más bien respondió a intereses económicos vinculados con las etapas de desarrollo económico del país, que contribuyeron a constituir un mosaico sumamente diferenciado de estructuras abastecedoras de productos específicos para la etapa agroexportadora, primero, y el mercado interno a escala nacional después.

La historia del territorio chaqueño giró en torno al algodón como el producto que le dio identidad. Así, el Chaco se especializó en la producción algodonera con sistemas de secano concentrados en el centro y sudoeste provincial. Desde 1920, el al- 
godón fue el cultivo por excelencia de los pequeños y medianos productores que abastecían el mercado local; el excedente se destinaba al mercado externo y, en consecuencia, el sistema de precios que lo regulaba no dependía de las cotizaciones internacionales, sino de la dinámica del consumo local y de la intervención reguladora del Estado (Rofman, 1999: 109). La coexistencia en el precario equilibrio de una amplia constelación de agentes productivos y una mayoría de pequeños agricultores, fue posible gracias a la intervención estatal directa o indirecta.

La limitada flexibilidad productiva orientada a completar la canasta agropecuaria nacional, sumada al predominio de formas tradicionales y a una fuerte bipolaridad de la estructura agraria ${ }^{1}$ (grandes extensiones para la ganadería y la explotación forestal en la franja oriental y pequeños predios para la agricultura en el centro y sudoeste) determinaron una mayor vulnerabilidad potencial del sector agrícola chaqueño a los cambios en la demanda interna, a las oscilaciones de precios y a las coyunturas meteorológicas desfavorables.

En el terreno productivo esa vulnerabilidad quedó al descubierto a partir de la apertura económica y la desregulación de los mercados concretadas en la década de los noventa, en el marco de una serie de medidas conocidas como la retirada del Estado que dejó a los sectores mayoritarios de esa producción sin la red de contención legal que habilitó su sostenimiento durante este siglo.

La expansión de la soya desde mediados de los noventa supuso una inserción subordinada, coyuntural y complementaria como periferia ampliada de la frontera pampeana, en un contexto de precariedad que hace prever una retirada apresurada ante la disminución de los beneficios temporales. A su vez, y a escala nacional, este avance de la soya no es más que el corolario de una problemática mucho más compleja referida a la mayor vulnerabilidad de las áreas marginales al complejo productivo pampeano. Es decir, en el enfoque subyace el tema del desarrollo desigual tan característico de los sectores agrarios de A mérica Latina, donde en las últimas décadas, y sin dejar de reconocer la pluralidad de situaciones, se ha ido consolidando lo que García Pascual (2003: 20) califica como una agricultura dual en la cual, por un

${ }^{1}$ En un extremo se concentran los grandes fundos de más de 1,000 ha, dedicados a la práctica ganadera extensiva, y en el otro se agrupan las pequeñas unidades agrícolas que en más de $66 \%$ de los casos no superaron las 200 ha en 2002. A su vez, dentro de este gran grupo es posible diferenciar entre los medianos y pequeños agricultores. Los primeros (17\% del total) poseen entre 100 y 200 ha y los pequeños representan el $49 \%$ restante y constituyen el grupo más vulnerable. 
lado, está una multitud de pequeñas explotaciones familiares, con niveles de inserción en el mercado muy dispares y empobrecimiento creciente $y$, por el otro, las grandes explotaciones ligadas al comercio internacional de materias primas agrarias que concentran los recursos y los medios de producción, y que también cuentan con un mayor acceso al capital, a los avances tecnológicos y a la información. La resistencia de la agricultura familiar tradicional admite múltiples matices en los países de América Latina, pero en todos los casos significa la defensa de la permanencia de la familia en el medio rural y la esperanza de mejorar su calidad de vida.

\subsection{Elementos conceptuales y criterios analíticos para el estudio del tema}

El enfoque que elegimos en este caso para analizar el tema es el estructural contextual ${ }^{2}$ que Sánchez H ernández (2003: 96) califica como dominante en la geografía económica actual y definido como el estudio de la lógica espacial del capitalismo. Esta perspectiva busca descubrir las formas en que el sistema capitalista, como estilo concreto de organización política de la actividad económica, se sirve del espacio geográfico (diferenciado y heterogéneo) para alcanzar su objetivo de acumulación, que implica un proceso continuado de expansión espacial y da lugar a la configuración de distintas modalidades de respuesta y adaptación territorial (local, regional, nacional, internacional, global) a los retos que plantea la articulación entre localización y acumulación. Para ello plantea el estudio espacial de las estructuras del sistema capital ista y la consideración de la influencia que el contexto o entorno geográfico, cultural mente construido por las sociedades humanas, tiene en su funcionamiento. El espacio económico deja de asimilarse a la llanura isotrópica para transformarse en un producto social, resultado material e histórico de las actividades y relaciones humanas.

Este enfoque parte del reconocimiento de la actividad económica como proceso político (desde la perspectiva de la economía política) para incorporar la esfera regulatoria como garante de la continuidad sistémica del capitalismo mediante sus sucesivas cri-

\footnotetext{
${ }^{2}$ Este proyecto participa de las dos formas de entender la geografía vigentes tras la crisis del positivismo: el estructuralismo de talante más o menos marxista y el humanismo fenomenológico animado por las filosofías posmodernas, ambos con un sentido crítico del capitalismo imperante y con sus consecuencias de desigualdad a todas las escalas.
} 
sis estructurales (escuela de la regulación). Esto conduce de forma natural a reparar en la función decisiva que instituciones y organizaciones tienen en esta labor de regulación y control social de la economía (enfoque institucionalista), para concluir con el reconocimiento de que tales instituciones y organizaciones tienen una raíz social y cultural que hace imprescindible comprender los contextos para explicar con profundidad las trayectorias económicas (giro cultural) y postular la imposibilidad de separar economía, sociedad y cultura en compartimentos estancos e inconexos (Sánchez H ernández, 2003: 98).

La posición adoptada para tratar el tema exige precisar los criterios de análisis. En primer lugar considera que sólo mediante un examen multiescalar de la trama territorial es posible la comprensión integral del problema. Esta mirada implica un tratamiento dinámico del contexto nacional para luego bajar a la situación provincial y, en última instancia, llegar a la escala del individuo con el estudio de casos para completar el reconocimiento y la interpretación de las diferentes posturas de los agentes que construyen esa trama. Esto no es sólo un viaje de descenso que termina en el terreno, porque desde este último se retorna hacia arriba todas las veces que la dinámica del estudio lo exige.

Esto implica una jerarquización selectiva de ciertos aspectos de la realidad. En primer lugar pone la atención en la particularidad de los lugares, la escala local como eje de la indagación para observar allí la dialéctica individual y colectiva entre el territorio y sus habitantes. Como señala Sánchez H ernández,

[... ] las nuevas corrientes y, sobre todo, el giro cultural, se desenvuelven mejor en las distancias cortas y en el marco de la proximidad. Al fin y al cabo, el estudio de la globalización, de los bloques comerciales [... ] se prestan más al análisis cuantitativo clásico basado en estadísticas y no tanto en el contacto directo con los agentes que animan la vida económica real y que se ha convertido en imperativo metodológico para la práctica de la geografía económica pospositivista (2003: 166).

Esto significa atender al conjunto de disposiciones -entendidas como las posturas y determinaciones de agentes diferenciados en sus motivaciones, posibilidades y expectativas- que resultan de la acción colectiva en un ámbito determinado, para comprender el fundamento del apego por ese entorno, que fue y es moldeado por lo que $\mathrm{H}$ arvey llama "Ias vidas transcurridas en un lugar" (2007: 191). 
A su vez, el examen de las posturas que reflejan identidades construidas histórica y espacialmente enraizadas precisa como base empírica el estudio de casos. Si bien estos casos reflejan coyunturas y no permiten generalizaciones, el otorgamiento de un estatus explicativo al estudio de las expresiones y la subjetividad de los actores supone considerar que las experiencias locales directas forman parte de la acción colectiva transcurrida en un ámbito determinado.

En el caso de este trabajo, en cuatro oportunidades se entrevistó a siete productores(as) de las colonias agrícolas del lote 33 Pampa Napenay y del lote 1 de la Colonia José Mármol (La M ontenegrina), ambas cercanas a la localidad de Sáenz Peña, segunda ciudad del Chaco y capital nacional del algodón. Las entrevistas en profundidad ${ }^{3}$ se realizaron en forma reiterada en cada caso, en junio de 2006, julio y diciembre de 2007 y febrero de 2008. Esta reiteración combinó preguntas ya hechas con nuevos interrogantes sobre cuestiones relativas a la producción algodonera y a las vivencias personales en torno de la misma.

La valoración de las opiniones de los productores tradicionales como cualitativamente relevantes presupone que los mismos contribuyen a ilustrar los procesos estudiados y comprender la amplitud y variedad de sus manifestaciones territoriales, porque esas acciones forman parte de redes de relaciones entre agentes sociales y una trama socioeconómica asentada sobre ciertos recursos natural es que se manifiesta en formas de producción, consumo e intercambio y en modos de organización y regulación específicos. Entorno e identidad se construyen y una mayor comprensión del contexto geográfico posibilita fundamentar el apego por ese entorno, moldeado por lo que $\mathrm{H}$ arvey llama "Ias vidas transcurridas en un lugar" (2007: 191). La interpretación de las respuestas de los productores, como resultados iniciales, proporciona evidencias de limitaciones y constituye el punto de partida para una abstracción ulterior que revele los factores estructurales que contribuyen a la persistencia de las posturas identificadas. A su vez, el cambio de escala para insertar esas

${ }^{3}$ Se trata de entrevistas abiertas individuales donde el entrevistador plantea temas o pregunta y deja que el entrevistado haga una interpretación a su manera y ritmo, sin fijar tiempos ni formas de responder. Esta técnica permite ir más allá de las opiniones superficiales para descubrir convicciones, experiencias y percepciones que afloran sólo cuando el entrevistado lleva la iniciativa y se explaya, formulando las cuestiones en sus propios términos, entendiendo que una formulación demasiado directa podría hacer que se retraiga e incomode (Camarero, 2006: 189-190). 
posturas en la dinámica nacional, posibilita la identificación de lógicas territoriales en los procesos en curso.

La consideración de niveles de acción -individual y colectiva- en los cuales se construyen esas cuestiones, exige una especificación conceptual acerca de la variedad de escalas jerárquicas en las que se organizan las actividades humanas, la cual implica en su esencia discordancias entre fuerzas de magnitudes y efectos diferenciales, así como diferencias significativas con las escalas dominantes dos 0 tres décadas atrás. ${ }^{4}$

En relación con el tema de la escala, Javier Gutiérrez Puebla (2001: 90) señala la necesidad de distinguir en primera instancia a la misma como categoría ontológica y como categoría epistemológica. En la primera, la idea de escala se asocia a la perspectiva que adopta el ser humano para aprehender y contextualizar la realidad; en la segunda, la escala significa adoptar un nivel (magnitud, dimensión) a partir del cual se ha de analizar la realidad.

Para precisar el concepto y los alcances del término escala, este autor establece cuatro concepciones: la escala como tamaño, como nivel, como red y como relación. La primera se corresponde con la escala cartográfica y establece órdenes de magnitud y de nivel de detalle o resolución. El segundo concepto alude a la escala como nivel jerárquico (local, nacional, global), mientras que la escala como red rechaza la idea de escala asociada a determinadas áreas y niveles y plantea la idea de redes de agentes que operan en distintos grados y profundidades de influencia. Por último, el concepto más rico y de mayor potencial para el análisis geográfico es la escala como relación, apoyada en la idea de que cuando se cambia de escala, los elementos que se contemplan pueden ser básicamente los mismos; lo que cambia son las relaciones entre ellos y el modo en que destaca el papel que juegan, adquiriendo algunos una importancia diferencial. Esta relatividad en la visión de un mismo hecho desde distintas escalas genera conflictos vertical es (entre la escala local con la regional y ésta con la nacional) y conflictos horizontales (entre localidades, entre regiones, entre naciones) (Gutiérrez Puebla, 2001). $\mathrm{N}$ ecesariamente, el examen de estas prácticas involucra una je-

\footnotetext{
${ }^{4}$ David $\mathrm{H}$ arvey advierte sobre la necesidad de estudiar los hechos en distintas escalas, como una garantía de amplitud en cualquier enfoque y para evitar sobredimensionar la importancia puntual de factores o elementos, pues "un error común tanto de la interpretación analítica como de la acción política se produce porque demasiado a menudo nos encerramos en una sola escala de pensamiento [...]. El resultado final es que todas las formas de pensar que operan sólo en una escala se vuelven al menos cuestionables, si no directamente engañosas" (2003: 101).
} 
rarquización que Santos (2000: 126) expresa con claridad cuando diferencia entre la escala de origen de las fuerzas operantes que dan sustento a esos procesos (la cual se relaciona con la potencia del emisor) y la escala de impacto, que tiene que ver con una variedad de respuestas territoriales.

En la dialéctica multiescalar de fuerzas de distinta magnitud, la constante articulación de energías diferenciales suscita reacciones de adaptación y de resistencia a los impulsos en juego. Por lo que el análisis de estas interacciones requiere distinguir ciertos aspectos, como la vulnerabilidad selectiva de los agentes involucrados y la variedad de filtros o mediaciones existentes, para resolver la regulación de la apertura hacia fuerzas de distintas magnitudes potenciadas en un espacio concreto.

En este caso de análisis, nos interesa particularmente un aspecto, que Bourdieu distingue como "el conjunto de las disposiciones del agente económico como producto paradójico de una larga historia colectiva reproducida sin cesar en las historias individuales" (2001: 19) inscritas paralelamente en estructuras sociales y estructuras cognitivas, en esquemas prácticos de pensamiento, percepción y acción. La dialéctica individual y colectiva entre el territorio y sus habitantes, con sus preferencias y necesidades, previsiones, esperanzas y posibilidades que en palabras de este autor "dependen de una historia, que es la misma del cosmos económico en que se exigen y recompensan" (Bourdieu, 2001: 22).

Desde esta perspectiva, el objetivo es examinar la coexistencia territorial de dos lógicas de actuación sustentadas por agentes diferenciados en sus motivaciones, posibilidades y expectativas. En estas lógicas (observables en las estrategias de uso del suelo) es posible identificar una interacción de fuerzas desiguales que cristaliza en manifestaciones de aceptación y de reticencia a los impulsos en juego. La lógica de la resistencia que sostienen los esquemas tradicionales de tipo familiar arraigados históricamente en el espacio productivo del Chaco, no se opone a las nuevas tendencias difundidas en los últimos 10 años, sino que aspira a una pervivencia digna, en un planteamiento de reproducción de opciones con un fuerte componente identitario asociado al cultivo del algodón. La lógica de adopción de las nuevas tecnologías de insumos y procesos de los cultivos transgénicos intenta imponerse mediante las acciones de nuevos agentes que se incorporan al territorio con una dinámica distinta. 
Para comprender esta dinámica es necesario contextualizarla por medio de la historia multiescalar de la trama territorial, Io cual implica examinar el contexto nacional para luego bajar a la dinámica provincial y, en última instancia, llegar a la escala del individuo con el estudio de casos para completar el análisis y la interpretación de las diferentes posturas de los agentes que construyen esa trama.

\section{El contex to nacional: transformaciones del sector agrario argentino en los últimos 15 años}

Los cambios en el sector agrícola argentino se aceleraron en 1991 con la implementación del Plan de Convertibilidad, un nuevo programa económico que significó un punto de ruptura en la evolución de la economía argentina. Éste tenía cuatro pilares fundamentales: la ley de convertibilidad, la desregulación de la actividad económica, las políticas de privatizaciones y la apertura externa (G hezán et al., 2001: 7-8). Los años siguientes significaron el debilitamiento de la institucionalidad que caracterizaba a la intervención estatal en la agricultura y en el medio rural, cuyos efectos se potenciaron por su combinación con la tendencia expansiva de los agronegocios y la creciente integración del sector agrícola a los complejos agroindustriales. I gualmente importantes fueron las políticas de descentralización, orientadas a otorgarle mayor autonomía a instancias de gestión local y regional (Sepúlveda et al., 2003: 17, 24).

La segunda etapa de cambios comenzó en 1996 cuando se liberó la venta la soya genéticamente modificada (RR), ${ }^{5}$ cuya implantación trajo consigo un paquete tecnológico que combinó el sistema de siembra directa, ${ }^{6}$ el uso intensivo de biocidas (glifosato) y fertilizantes, lo que significó la posibilidad de adoptar rápidamente un paquete tecnológico en un modelo de fuga hacia adelante, apoyado fundamentalmente en una importante capacidad instalada previa. En esta etapa, el agro argentino exhibía simultáneamente modernización tecnológica, concentración productiva y endeudamiento creciente. Los procesos de modernización tecnológico-productiva del sector agrícola argentino, en la región

${ }^{5}$ Entre 1996 y fines de 2002 se libraron a la venta siete eventos de oGM (Bisang, 2003: 423).

${ }^{6}$ Ésta consiste en implantar la semilla sin necesidad de roturar la tierra en un único procedimiento de apertura y posterior aplastamiento de un surco, impone el uso de herbicidas que reduzcan al máximo la competencia de otras especies y también se complementa con el uso de diversos tipos de fertilizantes (Bisang, 2003: 430). 
pampeana central y en las economías regionales del norte, se concretaron sobre la base del crédito, abundante en la primera etapa de la convertibilidad. A mediados de la década, la situación dio un giro sustantivo por la baja generalizada de los precios internacionales y un creciente y progresivo endeudamiento, que acentuó particularmente la vulnerabilidad del sector ante acciones especulativas en el mercado de venta de la tierra. La rápida adopción del paquete soya RR/trigo/glifosato/siembra directa en un contexto de endeudamiento generalizado, fue la opción casi obligada. Las nuevas tecnologías acentuaron la pérdida de autonomía en la toma de decisiones de los productores agrícolas, lo que generó una nueva dependencia que los convirtió en meros consumidores del paquete tecnológico, la maquinaria y los asesores, en un cambio de perfil de la oferta que pasó a ser provista por centros de servicios, con lógicas altamente productivistas (Bisang, 2003: 434) y con una clara tendencia a la terciarización de operaciones junto con el desarrollo de una amplia red de subcontratistas.

El despegue de la soya fue impulsado por la duplicación del precio internacional de las semillas oleaginosas y del aceite, lo que hizo muy rentable la producción de ambos; un fuerte aumento del rendimiento por hectárea en los últimos 20 años (de $2.2 \%$ anual en la soya y de $4 . \%$ anual en el girasol) y la factibilidad de hacer un doble cultivo, de trigo en el invierno y de soya en el resto del año, duplicó la rentabilidad de la tierra (Secretaría de Agricultura, 2005).

La evolución desigual de las dinámicas productivas en un marco de fuerte especialización nacional en oleaginosas y cereales, dejó en situación desfavorable las áreas rurales especializadas en productos tradicionales de las provincias periféricas con escasas posibilidades de inserción en la dinámica exportadora y de agronegocios. Estas estructuras productivas regionales mostraron respuestas pasivas o regresivas, de tipo defensivo, para sobrevivir productivamente en condiciones precarias, con situaciones de endeudamiento crítico. Es el caso del sector de pequeños y medianos agricultores algodoneros del Chaco, la principal provincia productora de esta especie y que aportó históricamente de $70 \%$ a $85 \%$ de la producción del país, de acuerdo con los censos nacionales agropecuarios. A partir de 1998 esta jurisdicción dejó de ser la principal provincia algodonera argentina para incorporarse a la producción de soya transgénica. Este cambio fue el más importante en el desarrollo del sector agrícola provincial, porque significó que se relegara el oro blanco, cultivo que 
sustentó la ocupación y organización económica del territorio chaqueño desde 1920. El proceso que nos ocupa constituye, como señala Aparicio, "el ejemplo más dramático de la reestructuración de la agricultura argentina" (2005: 210). ${ }^{7}$

A partir del Plan de Convertibilidad y la devaluación del peso argentino en 2002, el contexto de precios internacionales favorables a productos como la soya y los nuevos escenarios de negociación comercial (aLCA y Unión Europea) configuraron un contexto de reactivación que se dio en llamar el salto exportador argentino. Éste se acompañó de una expansión vigorosa del consumo y la inversión en el marco de una posición fiscal con superávit. Entre 2002 y 2005 (Secretaría de Industria, 2003, 2006) los productos primarios y las manufacturas de origen agroindustrial (MOA) contribuyeron con 53\% del total de exportaciones. Dentro de las M OA, la importancia del complejo soyero es notable, ya que Argentina -junto con Estados Unidos y Brasil- constituyen los tres grandes productores en este rubro.

La mayoría de los complejos productivos nacionales encontró en la salida exportadora la oportunidad de crecimiento. Las dificultades surgieron en los primeros eslabones de los circuitos extrapampeanos, ${ }^{8}$ en las instancias que involucran a los productores agrícolas y las condiciones de su articulación contractual con los agentes comerciales vinculados a la exportación. Como señala un estudio de la CEPAL, "en las regiones más rezagadas de Argentina, algunos de los problemas principales se derivan de la debilidad de los agentes económicos y de su escasa capacidad para orientar progresivamente una trayectoria de expansión" (Gatto, 2003: 116).

La estructura de funcionamiento de los más destacados circuitos productivos instalados en la periferia del espacio regional, caracterizada por la coexistencia de agentes económicos con muy desigual poder de negociación se mantuvo inalterada luego de la

7 "Era la actividad con mayor incidencia de explotaciones familiares, las que llegaron a proveer cerca de $40 \%$ de la producción. En la campaña 2002-2003, la superficie total con algodón del país era la décima parte de la que se cultivaba 10 años atrás. Subsistieron los productores que pudieron incorporar las nuevas variedades y la cosecha mecánica" (Aparicio, 2005: 210).

${ }^{8}$ Tanto las economías regionales como el área pampeana se analizan cuantitativamente mediante la agregación de las provincias en grupos. Tradicionalmente, éstos son cinco: el pampeano (Buenos Aires, Córdoba, Santa Fe, La Pampa y Entre Ríos), el grupo de las provincias del nordeste (Corrientes, Formosa, Chaco y $\mathrm{M}$ isiones), el de las provincias del noroeste (Salta, Jujuy y Tucumán, La Rioja y Catamarca), el área de Cuyo (M endoza, San Juan y San Luis) y las provincias patagónicas (Río Negro, Chubut, Santa Cruz y Tierra del Fuego). 
devaluación. Como señala R ofman, "con excepción de la yerba mate, ${ }^{9}$ no se restablecieron mecanismos de intervención directa o indirecta del Estado en segmentos de dichos circuitos donde antes de los noventa regían mecanismos de regulación estatal 0 de autorregulación de precios" (2003: 392).

\subsection{Evolución de las tendencias productivas en el sector agrícola chaqueño}

En el Chaco el algodón fue el cultivo por excelencia de los pequeños y medianos productores desde 1920. Con la desregulación y apertura de la economía en los noventa esta producción especializada quedó sin protección ante los vaivenes de los precios en el mercado internacional. A mediados de esa década, si bien todos los agricultores se volcaron a producir algodón, el extraordinario incremento de la productividad y el aumento de los rendimientos obedecieron a las innovaciones tecnológicas incorporadas en los estratos de medianos y grandes productores. La producción creció mediante la difusión de sistemas mecanizados de cosecha, la introducción de nuevas variedades de mayor rendimiento y calidad, cosechas más tempranas - que acortaron el ciclo de cultivo y redujeron el periodo de recolección- y la ampliación del parque industrial de primera transformación. $\mathrm{N}$ uevas desmotadoras instaladas en esta etapa en la provincia encabezaron el proceso exportador donde Brasil recibía $90 \%$ de los envíos chaqueños.

M ientras se difundía la soja RR en el área pampeana, la euforia algodonera chaqueña se veía truncada por el descenso de los precios internacionales y las inundaciones ocurridas entre septiembre de 1997 y abril de 1998. Las perspectivas al entadoras dejaron paso a una crisis muy grave, por la magnitud del endeudamiento de pequeños y medianos productores (poseedores de explotaciones de menos de 100 hectáreas y de 101 a 200 hectáreas, respectivamente). El deterioro se fue agudizando, los precios pagados al colono por tonelada de algodón (que venían descendiendo desde 1997) cayeron aún más, los montos de las deudas de las cooperativas se incrementaron hasta llevarlas a la quiebra ante la imposibilidad de cumplir con sus obligaciones crediticias y las cosechas

\footnotetext{
${ }^{9}$ La yerba mate es un cultivo de plantación que desde 1935 reguló la Comisión Reguladora de la Producción y Comercio de la Yerba M ate (CRYM) hasta 1991. Con la sanción de la ley 25.564, del 21 de febrero de 2002, nace formalmente el Instituto $\mathrm{N}$ acional de la Yerba M ate (INYM), organismo que restablece la regulación de esta actividad.
} 
algodoneras a partir de 1999 fueron las peores en la historia del país. En ese contexto, los menores costos de implantación y la difusión de la siembra directa fueron los factores dominantes para la expansión de distintas variedades de soja en la provincia, "en un peligroso esquema de monocultivo que muchos dieron en llamar la soyarización de los campos chaqueños". ${ }^{10}$

La expansión de distintas variedades de soya determinó la coexistencia de dos sistemas productivos muy distintos: la soya genéticamente modificada (RR) con el paquete tecnológico biocidas-siembra directa, precios estables y comercialización segura en explotaciones medianas y grandes altamente capital izadas con modelos de manejo empresarial; y el algodón en unidades familiares con sistemas tradicionales de producción y diversos grados de capitalización, tecnología tradicional, mayores costos y falta de transparencia en el mercado de precios.

La prensa local sintetizó el proceso señalando que

El Chaco enfrentó dos elementos de suma gravitación para dejar de lado el tremendo efecto multiplicador del algodón; las permanentes pérdidas de los algodoneros tradicionales y la amplificada invasión de productores extraprovinciales, que ocuparon todos los espacios disponibles y volcaron más de 600,000 hectáreas a la soya excluyendo en muchos casos a los propios dueños de la tierra a resignarse a la renta anual. Esta nueva revolución granaria del Chaco, expresada en la fría estadística de la superficie cultivada, regocijaba a muchos, mientras el endeudamiento, la pérdida de la capacidad productiva y la "extranjerización de las tierras", tornaba más vulnerable aún al sistema productivo chaqueño y dejaba sin posibilidad de recupero y de pago de la deuda, como principales consecuencias en la colocación del moño y final a un sistema de monocultivo. ${ }^{11}$

El proceso de difusión e incorporación masiva de la soya centró su dinamismo en la ampliación de las fronteras cultivables y en mecanismos especulativos de tenencia temporal de la tierra, lo que generó un nuevo modelo de organización de la producción primaria basado en un fuerte predominio de la oferta de insumos ofrecidos por un número acotado de oferentes internacionales y sustentado por redes de distribución comercial privada. La elevación de la escala económica y las exigencias de capital requeridas para dedicarse a la agricultura, aceleraron la exclusión de los productores que por su situación de endeudamiento no pudieron elegir.

${ }^{10} \mathrm{~N}$ orte Rural, 8 de octubre de 2003, p. 5.

${ }^{11} \mathrm{~N}$ orte Rural, Suplemento, 15 de mayo de 2002, p. 2. 


\section{Figura I \\ Provincia del C haco, Argentina}

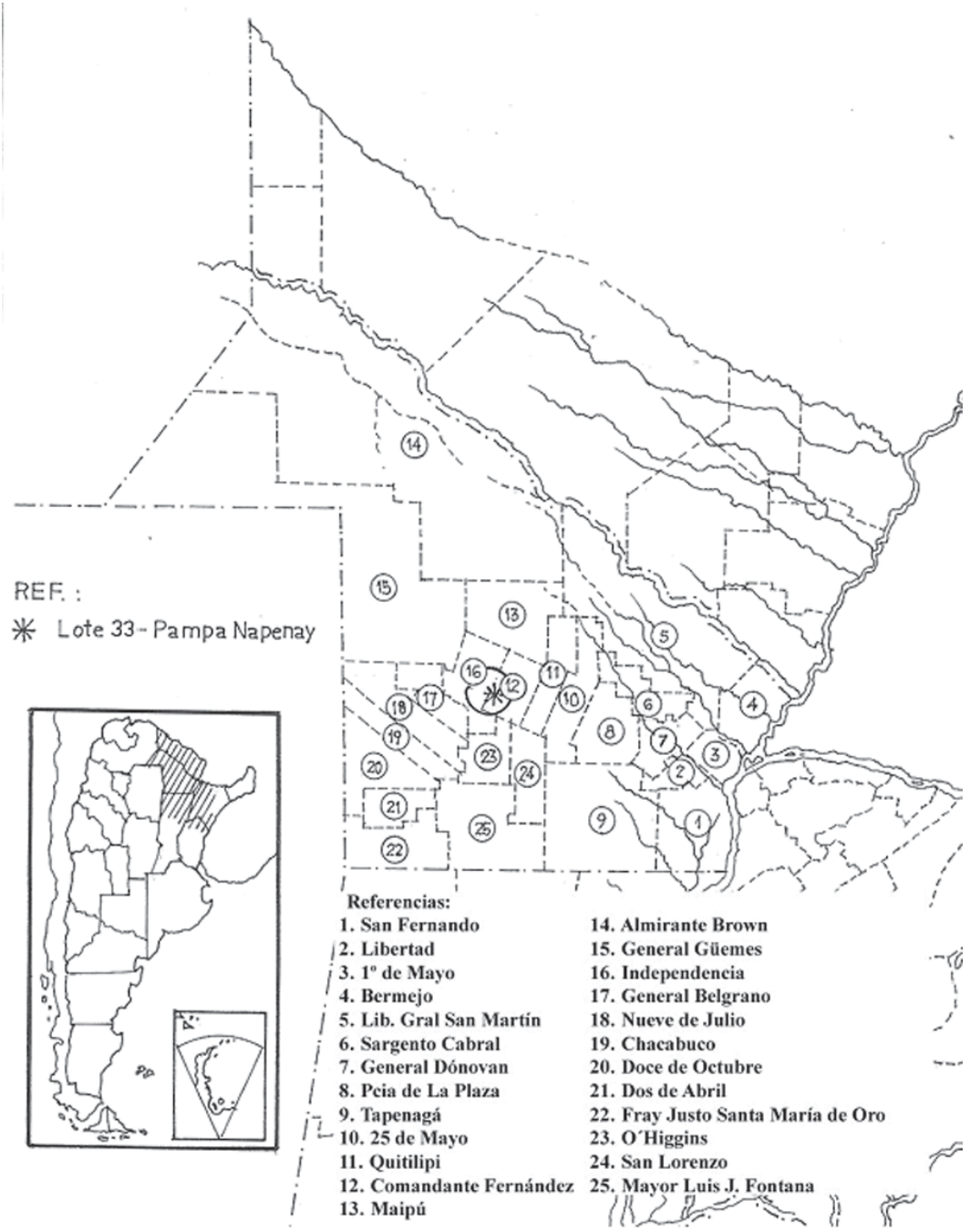

Fuente: Elaboración propia con base en $\mathrm{M}$ apa de la Provincia del Chaco, Instituto Geográfico M ilitar. Disponible en: http://www.igm.gov.ar/node/105. Fecha de consulta 10 de agosto de 2007. 
Con la expansión de las fronteras productivas tras la oleaginosa, en el Chaco se superó el millón y medio de hectáreas sembradas, incursionando en áreas no tradicionales, como en los departamentos Almirante Brown y General Güemes, que abarcan todo el extremo noroeste ( $42 \%$ de la superficie provincial) e incluyen el monte impenetrable. ${ }^{12}$ Las posibilidades ciertas de obtener dos cosechas por año agrícola, además de los bajos costos para acceder a la tierra fueron los ejes de esa ampliación dirigida por productores y empresarios del sur del país, que en significativa corriente migratoria y al ta capacidad de producción, arrendaron o adquirieron la mayoría de los campos con superficies superiores a 500 hectáreas.

Estos nuevos actores oriundos y residentes en provincias del área pampeana, introdujeron un conjunto de modalidades modernas y encontraron en el área sudoeste del Chaco extensiones suficientes para expandirse. La prensa provincial describió el fenómeno como "la invasión de productores ajenos a la provincia que compraron o alquilaron tierras y se dedican a la producción de soya. Es evidente que la vocación de esta gente es producir soya y no algún cultivo alternativo. La incógnita se basa en saber si este cambio estructural no tiene retorno, es circunstancial y puede ser revertido, y sobre esa base se puede pensar en volver a incrementar el cultivo de algodón o no".13

Considerando los dos últimos censos nacionales agropecuarios, el área algodonera localizada en el centro de la provincia, entre 1988 y 2002 registró una disminución de 1,957 explotaciones. Este total encubría dos tendencias: por una parte un aumento de 181 explotaciones de más de 500 hectáreas y, por otra, la tendencia más notoria fue una disminución de 2,138 explotaciones menos en dicho periodo para los estratos inferiores a 500 hectáreas. A su vez, dentro del gran grupo el número de explotaciones de menos de 100 hectáreas disminuyó en 1,439 explotaciones.

12 La comparación de los datos estadísticos de los censos nacionales agropecuarios de 1988 y 2002, por departamentos, demuestra que el área algodonera (centro-sudoeste) perdió más de 2,000 explotaciones y el área con nuevos cultivos de soya (departamento General Güemes, en el oeste), recientemente desmontada incorporó más de 800 explotaciones nuevas. La superficie agropecuaria provincial se incrementó en más de 400,000 ha y la extensión de la unidad agropecuaria promedio aumentó de 302,6 a 365,8 ha. Además, la provincia perdió, entre 1991 y 2001, 60,000 habitantes rurales.

${ }^{13}$ J uan Carlos Larramendy, N orte Rural, suplemento, 2 de julio de 2003, p. 7. 
Gráfica I

Algodón. Superficie cosechada, 1990-2007

Argentina y el Chaco

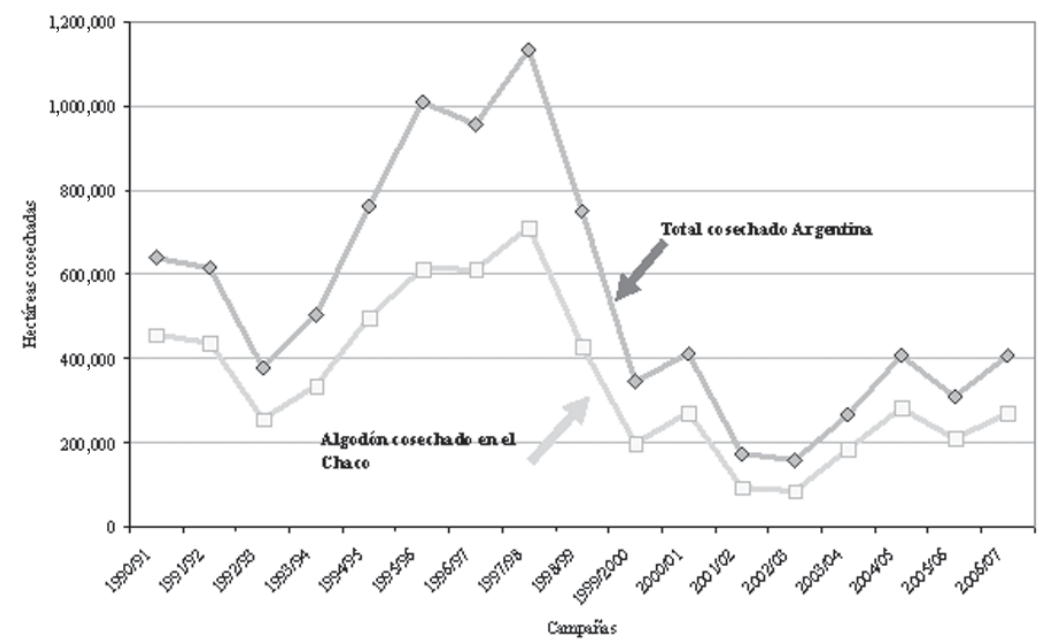

Fuente: Elaboración propia con base en datos del M inisterio de la Producción $(1998,2004)$.

C uadro 1

Variación en el número de explotaciones en el área algodonera del Chaco

\begin{tabular}{lrrr}
\hline & 1988 & 2002 & Diferencia \\
\hline M enos de 100 hectáreas & 4,066 & 2,627 & $-1,439$ \\
de 100 a 500 & 2,909 & 2,210 & -699 \\
500 a 1,000 & 392 & 431 & 39 \\
M ás de 1,000 & 178 & 320 & 142 \\
Total & 7,545 & 5,588 & $-1,957$ \\
\hline
\end{tabular}

Fuente: Elaboración propia con base en censos nacionales agropecuarios (1988, 2002). 


\section{Figura II \\ Provincia del Chaco, Argentina}

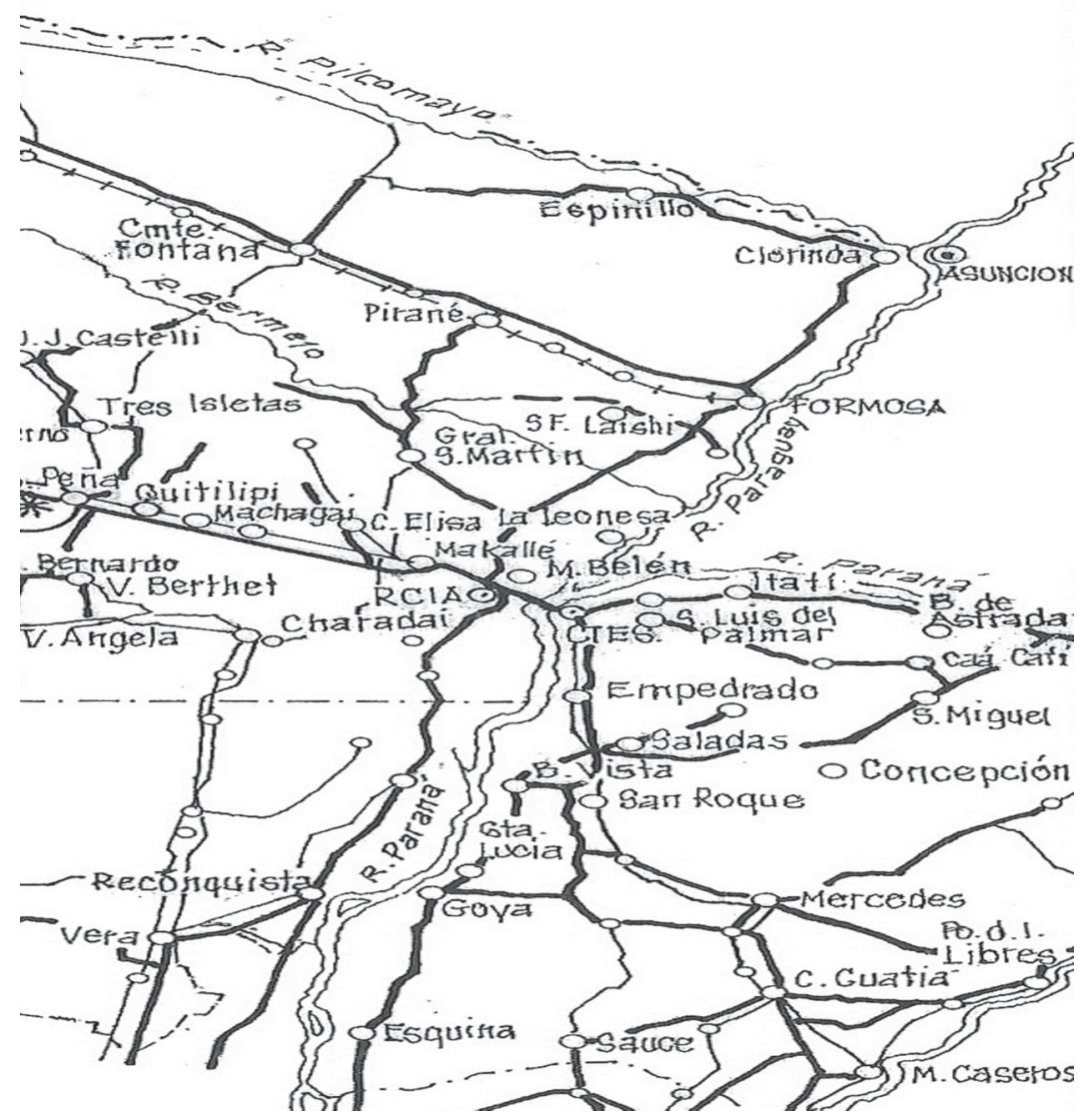

Fuente: Elaboración propia con base en M apa de la Provincia del Chaco, Instituto Geográfico M ilitar. Disponible en: http://www.igm.gov.ar/node/105. Fecha de consulta 10 de agosto de 2007. 


\section{La resistencia que sostienen los esquemas tradicionales de tipo familiar arraigados históricamente en el espacio productivo del $\mathrm{C}$ haco}

El mayor efecto de este proceso de crisis de la producción al godonera y difusión acelerada de la soya lo sintió el sector agrícola de pequeños (25 a 100 hectáreas) y medianos productores (de 101 a 200 hectáreas), que quedó altamente endeudado a fines de los noventa. El endeudamiento ${ }^{14}$ corresponde a los créditos tomados con el Banco N ación Argentina, con acreedores privados, proveedores de insumos y acopiadores, y obedeció a los buenos pronósticos que se habían trazado para el algodón a fines de la campaña 1996-1997. La apuesta al futuro materializada en la toma de créditos para la modernización tecnológica parecía el camino más lógico y aceptable, como expresaba en 1999 un productor: "Todos nos agrandamos, los colonos con tractores, con más hectáreas, se compraron cosechadoras, nosotros con las desmotadoras y hoy nos encontramos con que todo lo que se había dicho en reuniones con especialistas, que el futuro del algodón era bueno hasta el 2003 y al año nomás nos encontramos con la tremenda realidad de que esto no era así, los precios cayeron y se sumaron las condiciones climáticas que echaron por tierra cualquier posibilidad de producir en términos rentables". ${ }^{15}$

Esta apuesta para adelante fue una iniciativa común a los sectores agrícolas a escala nacional donde, como señala Bidaseca, “el discurso de la 'modernización' penetró en un principio cuando los hombres y mujeres del campo le adjudicaron credibilidad -'nos endeudamos porque creímos' - [... ] pero más tarde se enfrentó a sus prácticas y erosionó sus propios valores y creencias provocando un cuestionamiento de la legitimidad de ese orden que aparecía como natural, estableciendo de ese modo una ruptura con el mismo" (2004: 410).

Estos estratos de agricultores chaqueños endeudados y embargados (tierra y herramientas) e imposibilitados para cumplir

14 "Son 1,600 productores con 147 millones de pesos de deuda con el Banco $\mathrm{N}$ ación; ese monto es lo que sería para la provincia del Chaco en pesos y número de productores. Son los que tienen calificación de 5 y 6 , que son los créditos irrecuperables; pero en realidad ninguno es irrecuperable porque en sí persiguen el cobro, el cual está garantizado con hipotecas, son créditos recuperables (entrevista a Juana Vukich, realizada el 7 de julio de 2006 por Cristina Valenzuela y Liliana García).

${ }^{15}$ Testimonio de $\mathrm{N}$ icolás Czyruk, propietario de dos plantas desmotadoras en Tres Isletas, centro de la provincia del Chaco, N orte Rural, suplemento, 30 de junio de 1999, p. 5. 
con las obligaciones contraídas, de obtener nueva financiación y sin posibilidades de seguir produciendo según los modelos tradicionales, abarcaban $80 \%$ de los poseedores de explotaciones que van desde 25 a 200 hectáreas y en $70 \%$ de los casos a productores de 51 a 75 años). ${ }^{16}$ Estos segmentos invalidados por la coyuntura, con esquemas tradicionales de producción arraigados históricamente en el espacio productivo del Chaco, exhibieron distintas formas de resistencia para defender a sus familias de la pérdida de la tierra. Y esa resistencia que todavía sostienen, se sustentó en una identidad arraigada en varias generaciones que vivieron las penurias y las buenas cosas que tiene el campo en sus épocas de bonanza y han visto a sus mayores arrodillados frente al cultivo. No resistir, entonces, no era una opción, ya que sencillamente significaba traicionar esas raíces.

Ahora bien, las manifestaciones de esa resistencia adquieren distintas modalidades. En este trabajo se analizan dos de ellas: por una parte, el discurso y las prácticas reivindicativas que exhiben los productores algodoneros en su propia explotación y, por otra, la acción antagónica y comunicativa de una organización social surgida en este contexto para la defensa de los productores algodoneros quebrados y de la familia rural.

\subsection{Las formas de resistencia: discurso y prácticas de los productores algodoneros de acuerdo con el tamaño de la explotación}

Para comprender la variedad de reacciones y discursos en relación con el problema del algodón, es necesario señalar que el sector agrícola chaqueño no es ajeno a lo que Fiorentino et al. destacan como "los problemas estructurales más frecuentes de las economías regionales; la concentración de la propiedad fundiaria y la consiguiente división de los agricultores entre 'empresarios' y minifundistas dentro de una misma rama productiva" (1990: 367-394). M ientras los minifundistas chaqueños (poseedores de menos de 25 hectáreas) comparten una serie de rasgos negativos de índole diversa, como la imposibilidad de obtener excedentes suficientes, la dependencia del trabajo familiar, las escasas posibilidades de acceso a una oferta crediticia cara e insuficiente y la sujeción a los intermediarios que compran la pro-

16 "La deuda original de los productores con el Banco Nación no pasa de los 35 millones", declaraciones de la diputada provincial, doctora Viviana Glibota, N orte Digital, 16 de noviembre de 2006, http://visual03.visualhosting.net/ diario/. 
ducción a precios inferiores a los vigentes en el mercado; la situación de los agricultores con explotaciones progresivamente mayores, se va volviendo más desahogada al disponer de una mayor extensión y les posibilita un margen más amplio de opciones en su manejo productivo.

Analizando el discurso de productores residentes en el área algodonera tradicional del Chaco (Pampa Napenay, cercana a Roque Sáenz Peña, capital nacional del algodón), considerados informantes clave, se advierte una coincidencia general en la tradición que generó este cultivo cuya práctica en la zona data de hace más de 70 años.

Se trata de productores cuyos padres llegaron al Chaco en la década de los treinta y desde entonces han vivido de y para el algodón. Los entrevistados se han dedicado a este cultivo desde su infancia, cuando colaboraban en la cosecha junto a sus padres, y el resultado arroja 50 a 60 años con el algodón. En este sentido, es interesante comprobar, a partir de los testimonios de los propios agricultores, que la sujeción al algodón se fundamenta en un mandato familiar y también en la esperanza que alienta un cultivo enraizado en la tradición territorial. "Sembré algodón este año porque es lo que sé hacer desde hace muchos años [... ]. Soy al godonero desde hace 40 años". ${ }^{17}$ "Sembramos algodón este año porque somos algodoneros desde hace años. En mi familia hace 60 años que somos algodoneros. Yo comencé con el algodón en 1962, hace 45 años". 18

A la tradición identitaria con el algodón se suma lo que Rofman y García señalan como una limitación estructural que involucra al tipo de inserción del productor en el sistema productivo. Los pequeños productores tienen, por el tamaño de sus predios, una barrera al uso de la opción que los condena a mantenerse en el circuito algodonero. "Esa imposibilidad de rotar cultivos, por el tamaño del predio, se extiende a la ausencia de opciones hacia otras actividades agropecuarias intensivas, vedadas por la ausencia de planes y financiamiento con dicho objetivo" (2007: 16). ${ }^{19}$

${ }^{17}$ Entrevista a propietario de 29 hectáreas en el lote 33, Pampa N apenay.

${ }^{18}$ Entrevista a propietario de 142 hectáreas en el lote 33, Pampa N apenay.

${ }^{19} \mathrm{De}$ acuerdo con Rofman y García, "Si como sucede en la mayoría de las unidades agrícolas del área susceptible de ser utilizada para la explotación algodonera, la dimensión de las mismas es reducida por cuanto está en manos de un pequeño productor o un minifundista, tal reemplazo debe descartarse. Es decir, la opción soyera [...] parece como la única posible para el mediano o el gran productor pero no para el minifundista o el pequeño (2007: 16). 
La combinación de ambos factores explica que la disyuntiva de cultivar algodón aunque sea con pérdidas, es decir, la decisión de sembrar a pesar de la incertidumbre (ya no acerca de los márgenes de rentabilidad, sino si acaso ésta va a existir) ha pasado a formar parte de la cotidianeidad de los pequeños y medianos productores, que en muchos casos y hasta hace un par de años no perdían la esperanza de que un año bueno les permitiera mejorar su situación económica.

El desencanto derivado de la dedicación a un cultivo que en estos sistemas tradicionales de producción se caracteriza por los mayores costos y la falta de transparencia en el mercado de precios, convive con la esperanza de volver a poder, merced a la intervención reguladora del Estado, reclamada por los productores: “El gobierno tendría que hacer algo para que se pueda seguir viviendo en el campo, para que no nos saquen la chacra. Un precio sostén es lo que hace falta". ${ }^{20}$ "Q ue den créditos. El gobierno provincial debería fijar precio para la producción porque el subsidio es para el acomodado. Y lo que hace falta es un precio sostén, ya que el precio, es todo. ${ }^{21}$ "Voy a intentar un año más con el algodón. La solución principal pasa por el precio, por trabajar con rentabilidad y no seguir trabajando a pérdida, fundiendo el capital, y además hay que prohibir la importación de fibra". 22 "El gobierno provincial debería mejorar el precio. Tendría que haber un precio fijo de 1,500 pesos la tonelada y el gobierno nacional debería bajar las retenciones. Voy a seguir cultivando algodón sólo si mejora el precio, si cambia el precio no habría problemas para poder seguir sembrando, así te queda algo" ${ }^{23}$

En la comparación de los discursos, de acuerdo con el tamaño de las explotaciones, se advierte que a medida que éste aumenta, da paso a un mayor espectro de opciones en el manejo productivo, en el vínculo con las cooperativas y en los modos de financiación. Los intermediarios pasan de decir que es "un mal necesario" 24 y de querer "sacar toda la rentabilidad que pueden", ${ }^{25}$ a que esto no representa un problema, ya que sólo "hacen su negocio, a veces es conveniente, a veces, no" ${ }^{26}$

20 Entrevista a propietario de 29 hectáreas en el lote 33, Pampa N apenay.

${ }^{21}$ Entrevista a propietario de 50 hectáreas en el lote 33, Pampa $\mathrm{N}$ apenay.

${ }^{22}$ Entrevista a propietario de 142 hectáreas en el lote 33, Pampa N apenay.

${ }^{23}$ Entrevista a propietario de 300 hectáreas en el lote 1, Colonia J osé M ármol (La M ontenegrina).

24 Propietario de 142 hectáreas en el lote 33, Pampa Napenay.

25 Propietario de 50 hectáreas en el lote 33, Pampa Napenay.

${ }^{26}$ Propietario de 1,300 hectáreas en el lote 1, Colonia J osé M ármol (La M ontenegrina). 
La soya, con su paquete tecnológico y su mayor dependencia de los proveedores de insumos, es vista como una al ternativa "más rentable porque tiene menor gasto que el algodón, pero perjudica al pequeño productor". ${ }^{27}$ "La soya no ocupa mano de obra y el al godón es más difícil". ${ }^{28}$ Y los productores medianos y grandes ya la consideran una de sus mejores opciones: "Es un buen cultivo porque no tiene muchos gastos, es uno de los mejores". ${ }^{29}$ "La soya es un cultivo que se adapta bien a la zona y es relativamente fácil de manejar. El vuelco hacia la soya no fue una alternativa para la cooperativa, porque ésta fue hecha para el algodón y la soya no la ayudó". ${ }^{30}$ Los grandes productores exigen

... cerrar totalmente las importaciones de fibra ya que se importa normalmente cuando falta y cuando no, en la aduana se importa y exporta fibra y cae el precio. N osotros nos podemos autoabastecer, si se corta la importación se soluciona el problema. Cuando se importa fibra de Estados Unidos o de China la aduana no exige las mismas reglas que para la producción local, ya que los fardos que vienen del exterior están cubiertos por bolsas de yute. Y las industrias relacionadas con el cultivo del textil deberían estar más cerca de las zonas de producción, no tan lejos como es el caso de las hilanderías y las aceiteras. ${ }^{31}$

En suma, los riesgos de volcar todo el esfuerzo en un solo producto con un mercado aleatorio, como siempre ha sido el mercado algodonero, se relativizan notablemente según la disponibilidad de tierra. En términos generales, los agricultores que dispusieron de más de 100 hectáreas pudieron expandirse, diversificando su cronograma anual de cultivos en función del panorama de precios, criar ganado menor y mantener un modesto rodeo vacuno. Se mantuvieron relativamente informados acerca de los vaivenes de los precios internacionales del algodón e integrados institucional mente a cooperativas de producción. En cambio, para los agricultores que sólo contaban con predios de menos de 100 hectáreas y que siempre dependieron estrechamente para su producción de la mano de obra familiar, no resultó factible afrontar los gastos que implicó la ampliación del sistema productivo, por lo que concentraron sus esfuerzos en asegurar la supervivencia del grupo familiar y lograr un excedente que per-

27 Propietario de 50 hectáreas en el lote 33, Pampa Napenay.

28 Propietario de 142 hectáreas en el lote 33, Pampa N apenay.

29 Propietario de 300 hectáreas en el lote 1, Colonia J osé M ármol (La M ontenegrina).

${ }^{30}$ Propietario de 1,300 hectáreas en el lote 1, Colonia José M ármol (La M ontenegrina).

${ }^{31}$ Propietario de 1,300 hectáreas en el lote 1, Colonia José M ármol (La M ontenegrina). 
mitiera comprar semillas para la siguiente campaña, invirtiendo muy poco, para minimizar las pérdidas por distintas eventualidades, tanto meteorológicas como biológicas (plagas).

\subsection{Discurso y prácticas de la 0 rganización $M$ ujeres de la Producción (omp) del Chaco}

En este trabajo, el discurso colectivo de la resistencia se analiza a partir de una organización social que surge en el año 2001 para defender a los productores algodoneros quebrados y a la familia rural. El momento fundacional de esta organización se da a partir de la reunión de cinco mujeres pertenecientes a familias algodoneras, en la ciudad de Sáenz Peña, la segunda ciudad del Chaco y capital nacional del al godón, en enero de 2001. Como fecha oficial de surgimiento se considera el 26 de enero de 2001, día en que se constituyó el Estatuto del movimiento que se proponía luchar por "la protección, el desarrollo y crecimiento de la familia rural, lograr la permanencia de la familia en el medio rural y mejorar su calidad de vida". ${ }^{32}$

Dos meses después de su constitución, según palabras de su presidenta, "tuvimos el primer encontronazo con la realidad [...] fue cuando se hizo el paro general aquí, en el Chaco, se hizo en la rotonda de Roque Sáenz Peña, en los primeros días de marzo se reunieron más o menos 3,000 productores; estuvimos como tres o cuatro días precisamente solicitando un subsidio por lo que estaba viviendo el sector algodonero". ${ }^{33}$ Lo acontecido en esos días en el Chaco fue calificado como "la mayor concentración chacarera que se recuerde en la historia del $\mathrm{Chaco}{ }^{34} \mathrm{Combinando}$ varias medidas de protesta, los colonos se concentraron en la roton$\mathrm{da}$, donde convergen las principales rutas del territorio provincial, con maquinarias y tractores para impedir el paso por tiempo indeterminado. Al mismo tiempo, grupos de productores confluyeron en Sáenz Peña a partir de las cuatro de la madrugada ante las puertas de la sucursal del Banco $\mathrm{N}$ ación y de la Administración Federal de Ingresos Públicos (AFIP), con el objetivo de impedir su funcionamiento amontonando algodón en las puertas de acceso. ${ }^{35}$

32 Entrevista a Juana Vukich, presidenta de la ом р, el 23 de noviembre de 2006.

${ }^{33}$ Entrevista realizada por Liliana García y Cristina Valenzuela a la productora Juana Vukich, en la ciudad de Sáenz Peña, el 13 de julio de 2006 (en adelante: Entrevista 11/07/06).

${ }^{34}$ Diario N orte, Suplemento Chaco Adentro, 11 de marzo de 2001.

${ }^{35}$ Diario N orte, Suplemento Chaco Adentro, 11 de marzo de 2001. 
Como señala la presidenta y líder fundadora del movimiento, Juana Vukich, la batalla comenzó en ese momento, "no sólo por la crisis del sector, sino por la conservación de la herramienta básica del trabajo que es la tierra [...] De cierta manera fue, junto con otras entidades, una de las grandes batallas que nosotras libramos y que fuimos apoyadas, en realidad, por todos los productores [...] es decir, no fue fácil estar tres días y medio en la rotonda, asumiendo medidas de fuerza y que fuéramos escuchadas a nivel nacional". La motivación fundamental de las lideresas del movimiento pone el énfasis en la defensa de la identidad y de los estilos de vida, dado que "la mayoría de nosotras somos productoras; algunas somos hijas de productores, nos hemos criado en el campo, hemos vivido las penurias y las buenas cosas que ha tenido el campo en sus épocas de bonanza y hemos visto a nuestros padres arrodillados frente al cultivo, a veces, cuando las cosas no venían bien [...] entonces, era como traicionar nuestras raíces" (Entrevista, 11/07/06).

Las motivaciones que tienen sus miembros para participar se pueden expresar a partir de mecanismos que ponen en juego para evitar la marginación, en el marco de una política de identidad reivindicativa que busca conservar, al mismo tiempo, el sentimiento local de pertenencia y la apertura hacia el mundo (Berdoulay, 2002: 59). El espacio como contenedor de la memoria histórica aparece como una primera explicación y, tal vez, la que mejor se comprende del conjunto de causas que dieron origen al movimiento, constituido por "Ios que venimos de familias algodoneras, donde nuestros padres han sido 'algodoneros de raza'".

Vukich entiende que los medianos productores - de 100 a 250 ha- constituyen el sector más golpeado, "ya que es el sector que, hoy por hoy, está produciendo en muy malas condiciones, con tecnología muy atrasada, carentes de recursos desde el principio y durante la campaña, entonces está trabajando con base en el endeudamiento", el cual corresponde a los créditos concedidos por el Banco N ación Argentina, con acreedores privados, proveedores de insumos y acopiadores.

Desde su inicio, la o $\mathrm{m}^{36}$ ha basado gran parte de su cohesión interna y expresión pública en la acción, entendiendo por ello la 
movilización de sus integrantes y simpatizantes para generar 0 impedir determinados actos o eventos.

La confrontación inicial con los poderes públicos se concentró en detener las acciones del remate bancario (donde el principal acreedor es el Banco N ación) y de los acreedores privados, en tratar de encontrar las vías de diálogo para renegociar las deudas que crecieron de manera desproporcionada e intentando estrategias para tratar de solucionar el conflicto, mediante acuerdos de pago, considerando la deuda de capital de origen y proponiendo una reparación para que no se perdiera el suelo. Se trataba de "pelear el monto de la deuda" y al mismo tiempo "generar los recursos para cancelar nuestras obligaciones, porque si no es imposible". La evolución de la economía y la persistencia de las dificultades de los productores Ilevó a la om p a pedir "la reestructuración de la deuda de origen, teniendo como base de ello el capital registrado en la primera hipoteca del campo, además de pedirse la eliminación de intereses compensatorios, punitorios y el Coeficiente de Estabilización de Referencia (CER)". ${ }^{37}$

La principal modalidad de reclamo consistió en movilizaciones frente a sucursales del Banco $\mathrm{N}$ ación en el interior provincial, en particular en las localidades donde se concentran los productores endeudados que van a remate. Al mismo tiempo, la agrupación asiste constantemente a reuniones con los directivos de dicho banco en todo el país y con representantes de los distintos organismos vinculados al tema agrícola. Vukich destaca que "hemos tenido un sinnúmero de invitaciones al diálogo, tanto con el Poder Ejecutivo provincial como nacional (Senado), la SAGpya y el Banco N ación [... ]. La razón por la que nos escuchan es que no venimos a pedir por todos. Venimos por los que realmente tienen dificultades". ${ }^{38}$

\footnotetext{
adherentes y seguidores, que si bien no contribuyen con la cuota, participan de las movilizaciones y acompañan al movimiento (entrevista a Vukich, 21/11/06). La ом P realiza asambleas donde se levantan actas, en algunos casos con presencia de escribano, y tanto socios activos como adherentes y seguidores tienen voto en lo relativo a principios reivindicativos generales. En temas de definición interna, los socios activos son quienes pueden votar. El movimiento abarca toda la provincia, con la figura de las comisiones de delegadas que operan como elementos aglutinantes y captan las problemáticas locales. Las reuniones de productores han oscilado entre 150 y 300 asistentes. “En abril de 2005 se alcanzaron a reunir 500 productores frente a la plaza de la localidad de la presidencia de Roque Sáenz Peña" (entrevista a Vukich, 23/11/06).

Al 20 de noviembre de 2006, sumaban aproximadamente y en palabras de la Presidenta, 103 socios activos. Entrevista realizada el 20/11/06.

${ }^{37}$ Diario Norte, 1 de abril de 2006.

${ }^{38}$ Entrevista del 23 de noviembre de 2006.
} 
La pelea por el monto de las deudas implica buscar un punto de equilibrio entre lo que los productores están en condiciones de pagar y lo que

los otros estarían dispuestos a ceder sin que signifique una pérdida para ellos [...]. Pedimos que nuestras obligaciones se retrotraigan un poco porque están demasiado dimensionadas. Se busca el recál culo y la quita en las deudas, proponiendo pagar el capital de origen ("Io que se sacó como deuda histórica original") por estratos que van de 10,000 a 20,000 , de 20,000 a 50,000 y de 50,000 a 100,000, siendo éste el monto límite de la lucha y que abarca a $90 \%$ de los deudores en mora. El resto de las deudas, que se incrementó con las tasa de interés y el CER debe ser asumido por el Banco N ación como una "reparación histórica" para un sector duramente castigado por la coyuntura económica de los últimos años.

La organización, de acuerdo con sus propios registros de noviembre de 2006, había logrado la reestructuración o cancelación de las deudas en ocho casos, el impedimento de 12 remates directos y de aproximadamente 50 ejecuciones. ${ }^{39}$ En la medida que el movimiento fue creciendo, integró a agrupaciones más pequeñas, como la asociación Productores del Sudoeste, y fue acentuando la individualidad de sus acciones, con "medidas de fuerza propias, por cuerda separada, a pesar de que los reclamos son coincidentes". En este sentido, la o m p dejó en claro su disidencia con las medidas de protesta de la Federación Agraria. "Porque consideramos que no es la metodología -la del corte de rutas- adecuada. Y por la actitud de los dirigentes de FAA, que no reconocen el trabajo de las otras entidades". ${ }^{40}$ La modalidad del corte de ruta la practicaron los integrantes de la o m p sólo en tres ocasiones: en enero de 2001, junto con gran parte del espectro productivo provincial, y el 30 de abril y 1 o de mayo de 2003, en reclamo del pago del subsidio algodonero. ${ }^{41}$

La oм p amplió su discurso inicial circunscrito al tema del endeudamiento, a otro que incorporaba progresivamente una perspectiva integral de los problemas de los agricultores, sin que aquel primer eje reivindicativo fuera abandonado. Así, la temática de lucha fue incorporando el tema de seguridad rural, colaborando en la formación de un consorcio de productores afectados (Co-

${ }^{39}$ Entrevista del 21 de noviembre de 2006.

40 Juana Vukich, Diario Norte, 3 de octubre de 2006. Disponible en www.cuencarural.com/noticias/mujeres_de_la_produccion_no_acompanara_a_faa/.

${ }^{41}$ Entrevista del 23 de noviembre de 2006 ; Diario $\overline{\mathrm{N}}$ orte, Suplemento ${ }^{-}{ }^{-} \mathrm{Chaco}$ Adentro, 30 de abril de 2003. 
peder) a partir del cual se promovió la instalación de un destacamento policial en el departamento Independencia, y donde el delito rural disminuyó notoriamente. También el tema de la emergencia hídrica, el mejoramiento de caminos, la extensión de la electrificación rural, los problemas de desabastecimiento y el aumento de precio del gasoil, el mejoramiento de las condiciones edilicias y de la educación rural, en el marco de una estrategia general de mejoramiento de las condiciones de vida de la familia rural.

El fantasma de la expropiación es un tema recurrente en el discurso de la oм P; en este sentido, la mayoría de las entidades del sector coinciden en señalar que la falta de una política nacional que atienda a las realidades regionales, lleva a los bancos a dar el mismo tratamiento a los productores chaqueños que a los de la pampa húmeda, cuando las realidades del norte del país son sustancialmente distintas a las del centro y del sur. En relación con la reanudación de los remates de campos en diciembre de 2005, Vukich expresaba que "están destruyendo la unidad productiva, y da la sensación de que vienen por más". También hizo una fuerte advertencia que de continuar con "esta metodología de presionar a los productores, el campo se irá quedando desierto [...] de no frenarse la presión psicológica y económica" sobre los productores chaqueños que derivó en numerosos casos de ventas de sus campos para saldar la deuda que mantienen con la entidad crediticia, "se va a destruir la estructura productiva primaria, con centenares de agricultores expulsados a los pueblos y ciudades del Chaco, con un aumento considerable de inversionistas que se irán quedando con grandes extensiones de tierra [... E Está en juego el destino de centenares de productores del interior chaqueño que recibieron sus campos de sus padres 0 abuelos, y hoy están en la calle, en los pueblos, pidiendo un bolsón AIPo, 0 un plan jefe de hogar". ${ }^{42}$

El pedido de suspensión por un año de las ejecuciones y remates de campos y herramientas agrícolas, y de una solución definitiva al problema del endeudamiento de los productores con la entidad bancaria oficial, Ilevó a principios de enero de 2006 a las agrupaciones relacionadas con la producción primaria (M ujeres de la Producción del Chaco, Sociedad Rural Argentina, Asociación Productores del Sudoeste, Federación Agraria Argentina Filial Sáenz Peña y la Asociación de Productores Forestales), a

${ }^{42}$ Diario N orte, 18 de diciembre de 2005. 
plantarse frente a la sucursal del Banco de la N ación Argentina en la localidad de Campo Largo, ya que de esa sucursal salieron las primeras órdenes de remates y ejecuciones de campos de productores chaqueños, casos que fueron de los más sonados y que dieron inicio a la lucha de entidades agrarias para evitarlos.

La modalidad consistió en ubicarse frente al edificio del banco y colocar banderas y pasacalles frente a las puertas del mismo para impedir el funcionamiento normal de éste, permitiendo sólo el ingreso de los jubilados que iban a cobrar su pensión. El programa de protestas se realizó en distintas sucursales del Banco de la $\mathrm{N}$ ación Argentina, con el objetivo de lograr la suspensión de los remates por un año, así como mejores condiciones de reprogramación y recálculo de las deudas.

Como respuesta a la grave situación de los productores, surgió la ley 26.090, sancionada el 5 de abril y promulgada el 24 del mismo mes de 2006, declarando zona de desastre y emergencia económica y social para el periodo del 10 de febrero al 30 de noviembre de 2006 a determinados departamentos de la provincia del Chaco y disponiendo la creación de un Fondo Especial de Emergencia. Esta ley establece un periodo de gracia de un año a los productores para pagar las obligaciones impositivas y previsionales, además del refinanciamiento de sus deudas hasta en 120 cuotas mensuales, con quita de intereses resarcitorios y punitorios y eventuales condonaciones. La OPM, junto con la Asociación de Productores del Sudoeste, en septiembre de 2006 se encontraban en tratos para, dentro del marco de esta ley, establecer un subsidio para el sector agropecuario antes del vencimiento de la misma y teniendo en cuenta la crisis que atravesaba el sector en cuanto a las condiciones climáticas, el desabasto y la subida del precio del combustible. Para julio de 2007, la organización reclamaba al Poder Ejecutivo nacional el compromiso del pago en tiempo y forma de un subsidio algodonero destinado a afrontar las labores de siembra.

La organización trata de preservar una identidad decantada a través de generaciones: la del productor al godonero y busca conservar el perfil propio y desde esa base encontrar puntos de coincidencia con el resto de las entidades y el gobierno. Constituye un ejemplo de resistencia social con reivindicaciones muy específicas asociadas a coyunturas derivadas de la aguda crisis que vivió el país desde finales de los noventa. 


\section{Consideraciones finales}

La resistencia que sostienen los esquemas tradicionales de tipo familiar arraigados históricamente en el espacio productivo del Chaco es mucho más que una mera defensa de un sector endeudado y excluido. Es la lucha por la permanencia de la familia en el medio rural, la mejora de su calidad de vida y la conservación de la herramienta básica del trabajo: la tierra. Esa lucha se sustenta en una identidad arraigada en varias generaciones que han vivido el campo en sus épocas de bonanza y han visto a sus mayores arrodillados frente al cultivo. No resistir, entonces, no es una opción ya que significa, sencillamente, traicionar esas raíces.

Pero no sólo se busca evitar la marginación, también reivindicar una identidad que permita conservar, al mismo tiempo, el sentimiento local de pertenencia y la apertura hacia el mundo. Se pretende la inclusión en la medida en que ésta le otorgue la prioridad debida a la participación económica de la población rural, no para privilegiar formas precarias de producción, sólo porque éstas son las que predominan en una región, sino por medio de la aceptación de que las realidades locales exigen distintas estrategias de respuesta que reconozcan -en una primera instancia- sus necesidades específicas. Ello no implica el diseño de pobres estrategias para pobres (Sepúlveda et al., 2003), sino el rescate de alternativas productivas que reflejan tradiciones que resisten y que no se deben considerar a la ligera como recuerdos nostálgicos de un pasado más feliz. Aquí es donde cobra valor la dialéctica multiescalar que otorga importancia a las experiencias locales directas y a las abstracciones ulteriores que revelan los factores estructurales que contribuyen a la persistencia de las posturas identificadas, en un tratamiento dinámico que no es sólo un viaje hacia arriba que comienza en el terreno, sino que implica un enfoque dinámico del contexto nacional para luego bajar a la situación provincial y retornar a la base empírica todas las veces que la dinámica del estudio lo exige, con el objetivo de alcanzar una concepción más clara de la relación entre economía y territorio. Desde este enfoque, la resistencia propia de las familias algodoneras y sus organizaciones se asimila a las múltiples resistencias que se configuran ante la vertiginosa presión que ejercen las fuerzas o vectores de escala global en territorios económica y culturalmente diferenciados.

Esta reacción no se debe considerar de manera aislada, ya que de este modo su resultado sólo conduce (como lo hizo final- 
mente) a la reprogramación y condonación parcial de las deudas del sector de pequeños y medianos productores algodoneros, a partir de un acuerdo entre el gobierno provincial y el principal banco estatal acreedor. La consideración de la resistencia implica valorar el sentimiento local de pertenencia y el rescate de una visión humana de desarrollo, que permita la coexistencia no antagónica entre distintas lógicas de manejo de los recursos y de apertura territorial hacia el mundo, cuestiones que han cobrado indiscutible vigor y se presentan como una temática de creciente interés social en los discursos relacionados con los cambiantes escenarios de innovación tecnológica que plantea la globalización económica. Considerando que el desarrollo está asociado no sólo a la dotación de recursos y al tamaño de los mercados, sino en lo fundamental a un conjunto de esfuerzos y acciones de complementariedad tendentes a generar capacidades productivas y conocimientos especializados dentro de áreas geográficamente delimitadas. Se trata de fortalecer la capacidad de respuesta de la dimensión local - representada por las resistencias locales, como la o m p analizada en este estudio-, entendiendo que la jurisdicción deberá conectarse con los procesos globales, pero con un grado de autonomía relativa que le permita transformar su realidad, encontrando la forma de resolver equilibradamente la relación entre las fuerzas diferenciales que se asocian a intereses contrapuestos. Ello exige una política integral y multiescalar que impulse el desarrollo productivo de estas áreas marginales, partiendo de la idea de que las ventajas comparativas se pueden crear y que, por tanto, tienen una naturaleza dinámica apoyada en gran medida en la voluntad expresa del Estado de desarrollar la trama institucional de rescate y sostén del territorio y su bagaje histórico.

\section{Bibliografía}

Aparicio, Susana (2005), “Trabajos y trabajadores en el sector agropecuario de la Argentina", en N orma Giarraca y M iguel Teubal (coords.), El campo argentino en la encrucijada. Estrategias y resistencia sociales, ecos en la ciudad, Alianza, Buenos Aires, pp. 193-221.

Berdoulay, Vincent (2002), "Sujeto y acción en la geografía cultural: el cambio sin concluir", Boletín de la Asociación de Geógrafos Españoles, 34, M adrid, pp. 51-61. Disponible 
en: http://age.ieg.csic.es/boletin/34/3405.pdf. Fecha de consulta 8 de octubre de 2007.

Bidaseca, Karina (2004), "N egadas a la existencia y condenadas a la desaparición. Un estudio acerca de las luchas de las mujeres rurales en Argentina y Brasil desde la perspectiva de género", en Norma Giarraca y Bettina Levy (comps.), Ruralidades latinoamericanas. Identidades y luchas sociales, Consejo Latinoamericano de Ciencias Sociales (CLACSO), Buenos Aires, pp. 357-418.

Bisang, Roberto, (2003), "Apertura económica, innovación y estructura productiva", Desarrollo Económico. Revista de Ciencias Sociales, 43 (171), Instituto de Desarrollo Económico y Social, Buenos Aires, pp. 413-442.

Boudeville, J. R. (1966), Problems of Regional Economic Planning, Edinburgh University Press, Edimburgo.

Bourdieu, Pierre (2001), Las estructuras sociales de la economía, M anantial, Buenos Aires.

Camarero, Luis (coord.) (2006), M edio ambiente y sociedad. Elementos de explicación sociológica, Thomson, M adrid.

Coraggio, José Luis (1971), “Centralización y concentración en la configuración espacial argentina", trabajo presentado en el seminario organizado por la Secretaría del Consejo $\mathrm{N}$ acional de Desarrollo (Conade), Presidencia de la Nación, marzo de 1971, Buenos Aires, http://www.coraggio economia.org/jlc_publicaciones_r.htm.

Coraggio, José Luis (2000), "La relevancia del desarrollo regional en un mundo globalizado", ponencia presentada en el Seminario Taller Internacional "Cultura y desarrollo: la perspectiva regional/local", organizado por el Instituto Andino de Artes Populares del Convenio Andrés Bello (IADAP), Q uito, 15-17 de marzo, http://www.fronesis.org/ jlc_publicaciones_r.htm.

Fiorentino, Raúl, Javier Ekboir y Liliana Lunardelli (1990), “La ocupación de mano de obra rural en la Argentina", Desa- 
rrollo Económico. Revista de Ciencias Sociales, 30 (119), Instituto de Desarrollo Económico y Social, Buenos Aires, pp. 367-394.

García-Pascual, Francisco (2003), “El ajuste estructural neoliberal en el sector agrario latinoamericano en la era de la globalización", Revista Europea de Estudios Latinoamericanos y del Caribe, 75, Ámsterdam, pp. 3-29.

Gatto, Francisco (2003), Estudios de competitividad territorial. Componente A: Las estrategias productivas regionales. Debilidades del actual tejido empresarial, sistema tecnológico, financiero y comercial de apoyo, CEPAL-ONu, Buenos Aires.

Ghezán, Graciela, M ónica M ateos y Julio Elverdin (2001), Impacto de las políticas de ajuste estructural en el sector agropecuario y agroindustrial: el caso de Argentina, CEPAL, Santiago de Chile.

Gutiérrez Puebla, Javier (2001) "Escalas espaciales, escalas temporales", Estudios G eográficos, 62 (242), Instituto de Economía y Geografía-csic, M adrid, pp. 92-97.

Gutman, Graciela y Silvia G orenstein (2003), "Territorio y sistemas agroalimentarios. Enfoques conceptuales y dinámicas recientes en la Argentina", Desarrollo Económico. Revista de Ciencias Sociales, 42 (168), Instituto de Desarrollo Económico y Social, Buenos Aires, pp. 563-588.

H arvey, David (2003), Espacios de esperanza, Akal, M adrid.

H arvey, David (2007), Espacios del capital. H acia una geografía crítica, Akal, M adrid.

H irschman, Albert O . (1958), The Strategies of Economic Development, Yale University Press, N ew Haven.

M inisterio de Economía (2003), Resultados Definitivos. Censo Nacional Agropecuario 2002, INDEC, Buenos Aires. 
M inisterio de la Producción (1998, 2004), Estadísticas ganaderas y granjeras, Subsecretaría de Ganadería y Granja, el Chaco.

M yrdal, Gunnar (1957), Economic Theory and Undeveloped Regions, Routledge \& Kegan Paul, Londres.

Perroux, François (1991), L'économie du xxº siècle, Grenoble, Presses Universitaires de Grenoble, París.

Rofman, Alejandro (1986), "Políticas alternativas de transformación en el medio rural minifundista. La acción de las ONG en el área del nordeste", Revista Paraguaya de Sociología, año 23, 66, Centro Paraguayo de Estudios Sociológicos, Asunción, pp. 39-61.

Rofman, Alejandro (1995), “Economías regionales: diagnóstico y propuestas", en Silvia Cloquell y Eduardo Santos (comps.), Argentina frente a los procesos de integración regional: Ios efectos sobre el agro, H omo Sapiens, Rosario, pp. 231-232.

Rofman, Alejandro (1999), “Economías regionales. M odernización productiva y exclusión social en las economías regionales", Realidad Económica, 162, IADE, Buenos Aires.

Rofman, Alejandro B. (2000), Desarrollo regional y exclusión social, Amorrortu, Buenos Aires.

Rofman, Alejandro (2002), "Transformaciones regionales en la Argentina contemporánea. El perfil general del fenómeno", Alicia Raposo Castagna y M aria Isabel Woelflin (comps.) G lobalización y territorio, vı Seminario Internacional, Red Iberoamericana de Investigadores sobre globalización y territorio, Universidad N acional de Rosario, Rosario, pp. 101-123.

Rofman, Alejandro (2003), “Economías regionales. Perspectivas luego de la devaluación", en Plan Fénix. Propuestas para el desarrollo con equidad. Economías Regionales, Tercer Encuentro de Universidades $\mathrm{N}$ acionales, Facultad de Ciencias Económicas, Universidad N acional de Cuyo, M endoza, pp. 383-411. 
Rofman, Alejandro y Liliana García (2007), El desarrollo de las campañas algodoneras entre los años 2001 y 2005. Los encadenamientos productivos y la situación de los agentes económicos en el proceso de estancamiento y/o deterioro de la actividad, V Jornadas Interdisciplinarias de Estudios Agrarios y Agroindustriales, Facultad de Ciencias Económicas, UBA, Buenos Aires, disponible en CD.

Sánchez-H ernández, José Luis (2003), N aturaleza, localización y sociedad. Tres enfoques para la geografía económica, Universidad de Salamanca, Salamanca.

Santos, M ilton (2000), La naturaleza del espacio, Ariel, Barcelona.

Secretaría de Industria, Comercio y de la Pequeña y M ediana Empresa (2006), http://www.industria.gov.ar/cep/pancomexterior/estudios/2006/52_salto\%20exportador.pdf.

Secretaría de Planificación (1991), Censo Nacional Agropecuario, 1988, tomos 1, 17 y 18, INDEC, Buenos Aires.

Sepúlveda, Sergio, Rafael Echeverri y Adrián Rodríguez (2003), El enfoque territorial del desarrollo rural, Instituto Interamericano de Cooperación para la Agricultura, San José.

Recibido: 26 de noviembre de 2007. Reenviado: 18 de abril de 2008. Aceptado: 18 de julio de 2008.

C ristina 0 felia Valenzuela. Es doctora en geografía. Actualmente está adscrita al Instituto de Investigaciones G eohistóricas del Consejo N acional de Investigaciones Científicas y Técnicas (Conicet). Sus líneas de investigación actual son: desarrollo regional, ordenamiento territorial y problemas agrarios. Entre sus publicaciones destacan: "Los agentes locales del desarrollo rural. El accionar de las organizaciones cooperativas y solidarias, el sector empresario y el estado provincial, en la dinámica agrícola de los noventa en el Chaco", en M. M anzanal, G. N eiman y M. Lattuada (coords.), Desarrollo Rural. O rganizaciones, instituciones y territorios. Enfoques y experiencias, Ciccus, Buenos Aires, pp. 293-314 (2005); Transformaciones agrarias y desarrollo regional en el nordeste ar- 
gentino. (Una visión geográfica del siglo xx), La Colmena, Buenos Aires (2006); "Contribuciones al análisis del concepto de escala como instrumento clave en el contexto multiparadigmático de la geografía contemporánea", Investigaciones Geográficas, 59, Universidad N acional Autónoma de M éxico, M éxico, pp. 123-134 (2006); "Transformaciones y conflictos en el sector agrícola del Chaco en los noventa: articulaciones territoriales de una nueva racionalidad productiva", Mundo Agrario, 10, Universidad de La Plata, La Plata, pp. 1-34 (2005), http://163.10.30.203:9673/ mundo_agrario/numeros/numero10/.

Angel Vito Scavo. Es doctor en geografía por la Universidad $\mathrm{N}$ acional de Cuyo. Actualmente está adscrito al Instituto de Investigaciones $\mathrm{N}$ eohistóricas, del Consejo $\mathrm{N}$ acional de Investigaciones Científicas y Técnicas (Conicet). Sus líneas de investigación actual son: desarrollo regional, ordenamiento territorial y problemas agrarios. 